\title{
Recognition of the surface of a homeo domain protein
}

\author{
Joel L. Pomerantz, ${ }^{1,2}$ Thomas M. Kristie, ${ }^{1}$ and Phillip A. Sharp ${ }^{1,3}$ \\ ${ }^{1}$ Center for Cancer Research and Department of Biology, Massachusetts Institute of Technology, Cambridge, Massachusetts \\ 02139 USA; $^{2}$ Harvard-Massachusetts Institute of Technology Division of Health Sciences and Technology, Cambridge, \\ Massachusetts 02139 USA
}

\begin{abstract}
Homeo domain proteins exhibit distinct biological functions with specificities that cannot be predicted by their sequence specificities for binding DNA. Recognition of the surface of the Oct-1 POU homeo domain provides a general model for the contribution of selective protein-protein interactions to the functional specificity of the homeo domain family of factors. The assembly of Oct-1 into a multiprotein complex on the herpes simplex virus $\alpha / I E$ enhancer is specified by the interactions of its homeo domain with ancillary factors. This complex (C1 complex) is composed of the viral $\alpha$ TIF protein (VP16), Oct-1, and one additional cellular component, the $\mathrm{C} 1$ factor. Variants of the Oct-1 POU homeo domain were generated by site-directed mutagenesis, which altered the residues predicted to form the exposed surface of the domain-DNA complex. Proteins with single amino acid substitutions on the surface of either helix 1 or 2 of the Oct-1 POU homeo domain had decreased abilities to form the $\mathrm{Cl}$ complex. The behavior of these mutants in a cooperative DNA-binding assay with $\alpha$ TIF suggested that the Oct-1 POU homeo domain is principally recognized by $\alpha$ TIF in the $\mathrm{C} 1$ complex. The preferential recognition of Oct-1 over the closely related Oct-2 protein is critically influenced by a single residue on the surface of helix 1 because the introduction of this residue into the Oct-2 POU homeo domain significantly enhanced its ability to form a $\mathrm{C} 1$ complex.
\end{abstract}

[Key Words: Homeo domain; octamer-binding proteins; protein-protein interactions; POU domain; herpes simplex virus; $\alpha$ TIF(VP16)]

Received July 30, 1992; revised version accepted August 31, 1992.

Homeo domain proteins comprise a broad family of regulatory factors that are important determinants for morphogenesis, cell-type determination, and cell-type-specific functions in a wide evolutionary range of organisms (for review, see Gehring 1987; Scott et al. 1989; Affolter et al. 1990). The homeo domain motif consists of a DNAbinding domain that contains three $\alpha$-helices, and the determination of the structures of three homeo domainDNA complexes has revealed a general conservation of domain folding and DNA recognition among proteins with minimal amino acid sequence similarity (Kissinger et al. 1990; Otting et al. 1990; Wolberger et al. 1991). Most characterized homeo domains specifically recognize a DNA sequence containing a $5^{\prime}$-TAAT- $3^{\prime}$ core (Laughon 1991); but despite having similar DNA-binding specificities, individual homeo domain proteins confer extremely specific regulatory actions (for review, see Hayashi and Scott 1990). Furthermore, several studies suggest that the functional specificity of homeo domain proteins is largely determined by a minimal region containing the homeo domain (Kuziora and McGinnis 1989; Gibson et al. 1990; Malicki et al. 1990; Mann and Hogness 1990; McGinnis et al. 1990; Furukubo-Tokunaga et

${ }^{3}$ Corresponding author. al. 1992; Lin and McGinnis 1992). For example, the replacement of the homeo box sequences of the Deformed gene of Drosophila melanogaster with the homeo box sequences in the Ultrabithorax gene targets regulation by the chimeric gene in vivo to those sites that are normally controlled by Ultrabithorax. This change in specificity occurs even though the DNA-recognition helices of these two homeo domains are essentially identical (Kuziora and McGinnis 1989; Lin and McGinnis 1992). A critical question, therefore, concerns how homeo domain regulatory specificity is determined.

One possible mechanism for the determination of the biological specificity of homeo domains invokes interactions with other regulatory proteins. Although a single homeo domain may have the potential to bind to many target promoter sites, it may be specifically recruited into a functional complex at only a subset of those sites by selective protein-protein interactions.

An excellent system for studying interactions between homeo domains and other proteins involves the differing abilities of two highly homologous proteins, Oct-1 and Oct-2, to assemble into a multiprotein complex on the herpes simplex virus (HSV) $\alpha /$ IE enhancer element. This element $\left(5^{\prime}\right.$-ATGCTAATGATATTCTTTGG-3') is required for the transcriptional regulation of the five viral $\alpha$ genes (Mackem and Roizman 1982a,b,c; Kristie and 
Roizman 1984; Gaffney et al. 1985; Bzik and Preston 1986; for review, see McKnight et al. 1986) and is recognized by a multiprotein complex ( $\mathrm{Cl}$ complex) that contains Oct-1, the viral factor $\alpha$ TIF (VP16, Vmw65, ICP25) (McKnight et al. 1987; Gerster and Roeder 1988; O'Hare and Goding 1988; Preston et al. 1988; Kristie et al. 1989; Stern et al. 1989), and at least one additional cellular factor, the $\mathrm{Cl}$ factor (Kristie et al. 1989; Xiao and Capone 1990). The $5^{\prime}$ portion of the enhancer element consists of a homolog of the consensus octamer site (5'-ATGCAAAT $-3^{\prime} \mid$ and is specifically recognized by the Oct-1 POU domain (Kristie and Sharp 1990), which contains POU-specific and POU homeo subdomains characteristic of the POU domain subclass of homeo domain factors (Herr et al. 1988). The remainder of the element is recognized by $\alpha$ TIF and possibly by components of the cellular Cl factor (Kristie and Sharp 1990).

Initial analyses of the $\mathrm{Cl}$ complex suggested that most, if not all, of the Oct-1 determinants that mediate protein-protein interactions in the formation of the $\mathrm{Cl}$ complex are contained in the POU homeo domain of the protein (Kristie and Sharp 1990). However, despite a high degree of homology with Oct-1 in the region of the POU homeo domain and an apparently equivalent ability to bind to the DNA element, Oct- 2 had a 100-fold lower potential to form a Cl complex (Kristie et al. 1989; Stern et al. 1989|. Although interactions between Oct-1 and $\alpha$ TIF have been demonstrated in the absence of the $\mathrm{Cl}$ factor (Kristie and Sharp 1990; Stern and Herr 1991), it remains unclear which component of the $\mathrm{C} 1$ complex is responsible for the selective recognition of the Oct-1 POU homeo domain.

Site-directed mutagenesis has been used to determine which amino acids are important for the recognition of the Oct-1 POU homeo domain in the formation of a Cl complex. The results indicate that residues on the surface of both putative helices 1 and 2 are important in the selective protein-protein interactions and that a single amino acid substitution in helix 1 of the Oct-2 POU homeo domain promotes significant interaction of this protein with components of the $\mathrm{C} 1$ complex. In addition, evidence is presented that $\alpha$ TIF is the component of the $\mathrm{Cl}$ complex which is principally responsible for the recognition of the Oct-1 POU homeo domain. This study demonstrates that individual amino acid differences between highly related homeo domains can dictate functional specificity through specific protein-protein interactions with regulatory factors.

\section{Results}

\section{Differing abilities of the Oct-1 and Oct-2 POU homeo domains to participate in C1 complex formation}

The Oct-1 and Oct-2 POU homeo domains were produced as Staphylococcus protein A (PA) fusion proteins and compared in an electrophoretic mobility shift assay (EMSA) for their potential to form the $\mathrm{C} 1$ complex (Fig. 1). As observed previously (Kristie and Sharp 1990), the Oct-1 POU homeo domain binds to the $\mathrm{HSV} \alpha 0$ probe, which contains the $\alpha$ /IE element, cooperatively as a homodimer (lane 3 ) and forms the multiprotein $\mathrm{Cl}$ complex upon addition of $\alpha$ TIF (PA- $-\alpha$ TIF) and a chromatographic fraction of HeLa cell nuclear extract containing the $\mathrm{Cl}$ factor (lane 4). The Oct-2 POU homeo domain, however, generates a complex on the $\alpha /$ IE element with the expected mobility of a monomeric protein-DNA complex (lane 5) and does not form a Cl complex in the presence of $\alpha$ TIF and the C1 factor (lane 6). Thus, the Oct- 1 and Oct-2 POU homeo domains differ in both the potential to dimerize on the $\alpha /$ IE element and in the ability to interact with the $\alpha$ TIF and $\mathrm{Cl}$ factors. As will be shown later, the ability to bind as a dimer is not related to the potential to form a $\mathrm{Cl}$ complex. Furthermore, both proteins bind as monomers to a probe containing a consensus octamer site with comparable affinity (data not shown). Clearly, the POU homeo domains of Oct-1 and Oct- 2 contain determinants that mediate their discrimination by $\alpha \mathrm{TIF}$, the $\mathrm{Cl}$ factor, or both.

\section{Residues in the Oct-1 POU homeo domain involved in C1 complex formation}

Amino acid residues in the Oct-1 POU homeo domain

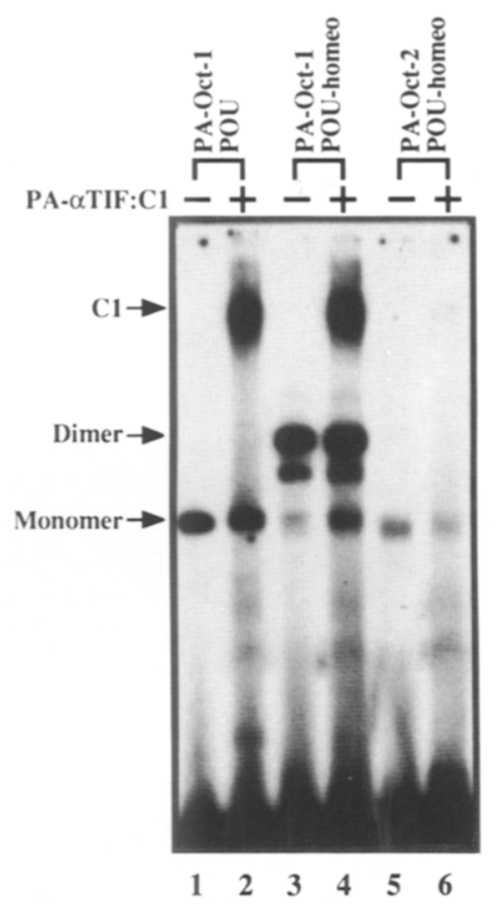

Figure 1. Comparison of Oct-1 and Oct-2 POU homeo domains in the assembly of a $\mathrm{Cl}$ complex. DNA-protein-binding reactions were done as described in Materials and methods. The probe DNA, HSV $\alpha 0$, contains the $\alpha /$ IE element from -168 to -142 of the $\alpha 0$ promoter. Protein A fusion proteins containing the Oct-1 POU domain (100 pg), the Oct-1 POU homeo domain (100 ng), or the Oct-2 POU homeo domain (100 ng) were incubated in the absence $(-)$ or presence $(+)$ of $15 \mathrm{ng}$ of PA- $\alpha$ TIF and $1 \mu \mathrm{l}$ of a chromatographic fraction containing the HeLa cell $\mathrm{Cl}$ factor as indicated. The positions of the multiprotein $\mathrm{Cl}$ complex as well as the monomeric and homodimeric Oct-1- or Oct-2-DNA complexes are indicated with arrows. 
that are most likely to mediate specific protein-protein interactions would be expected to be located on the physically available surface of the DNA-bound domain and to be divergent among members of the POU domain family of factors. A model of the Oct-1 POU homeo domain (Fig. 5, below) was generated by aligning its sequence with that of the engrailed homeo domain and positioning its amino acids based on the crystal structure of the engrailed homeo domain-DNA complex (Kissinger et al. 1990). A comparison of the POU homeo domain amino acid sequences among representatives of the different classes (He et al. 1989) of POU domain proteins is depicted in Figure 2A. The regions that contain the most highly conserved residues within this family are boxed. The amino acid sequence of the engrailed homeo domain is listed for comparison, and the positions of residues that have been noted in the structural studies to be involved in packing of the hydrophobic core or in homeo domain-DNA interactions are indicated. Most of these positions lie within regions that are highly conserved among POU domain factors, as would be expected if homeo domain structure and DNA recognition are generally conserved. The unboxed or divergent amino acids could be responsible for factor-specific protein-protein interactions that contribute to the functional specificities of these proteins. Helical wheel representations (Fig. 2B) of helices 1 and 2 of the Oct-1 POU homeo domain predict that the divergent residues, including those that differ between Oct-1 and Oct-2, comprise the surface expected to remain physically accessible upon DNA binding.
Thus, both the modeled structure of the Oct-1 POU homeo domain and the sequence comparison of several POU domain proteins define a common set of amino acids that are likely to be responsible for protein-protein interactions and were therefore targeted for site-directed mutagenesis. The substitution of these amino acids would not be expected to disrupt either the structure of the domain or its ability to bind DNA. Because the amino acids that are different between Oct-1 and Oct-2 in the region of the POU homeo domain must contribute to the differential ability of these proteins to interact with components of the $\mathrm{Cl}$ complex, the appropriate Oct-1 residues were substituted with the corresponding Oct- 2 residues. Other amino acids in the selected set were mutated so as to remove potentially important functional groups or to alter the character of a particular residue (i.e., from positive to negative, hydrophobic to polar, and vice versa). All of the constructed variants of the Oct-1 POU homeo domain were expressed in Escherichia coli as PA fusions and purified by chromatography on IgG-Sepharose. To test their structural integrity and their capacity to bind DNA, all mutants were titrated into reactions containing an octamer consensus site probe. All mutants bound with affinities that were comparable with that of the wild-type protein /data not shown).

Each mutant polypeptide was tested for the ability to bind to the $\alpha /$ IE element and to interact with the $\alpha$ TIF and $\mathrm{Cl}$ factors in a $\mathrm{Cl}$ complex assembly assay. The proteins were titrated into reactions containing the $\alpha / \mathrm{IE}$ element and were found to cooperatively form ho-
A

OCT $3 / 4$
UNC 86
BRN 3
TST 1
BRN 1
PIT 1
OCT 2
OCT 1
ENGR

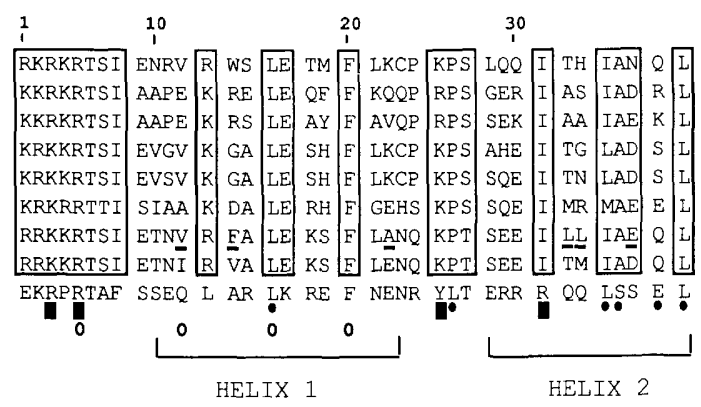

40

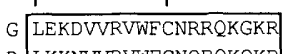

D LKKNVVRVWECNQRQKQKR

D LKKNVVRVWE CNQRQKQKR

Q LEKEVVRVWFCNRRQKEKR

Q LEKEVVRVWECNRRQKEKR

N LEKEVVRVWFCNRRQREKR

H MEKEVIRVWFCNRRQKEKR

$\mathrm{N}$ MEKEVIRVWFCNRRQKEKR

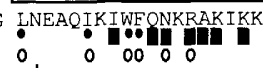

0

HELIX 3

B
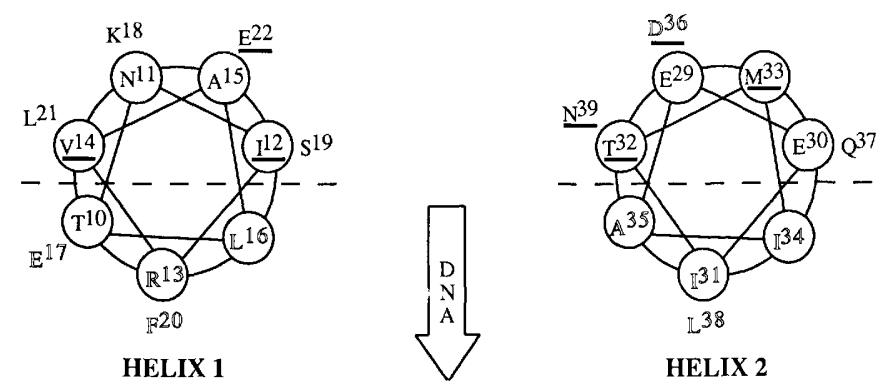
acids that differ between Oct- 1 and Oct-2 are underlined. The broken line divides the helices into two halves, the lower of which is predicted to pack against helix III and face the DNA in a protein-DNA complex.

Figure 2. $(A \mid$ Comparison of POU homeo domain amino acid sequences among several POU domain factors. Amino acids that are highly conserved in the POU homeo domain of proteins representing the different subclasses (He et al. 1989) of POU domain factors are boxed. The 7 amino acids that differ between Oct- 1 and Oct- 2 are underlined. The positions occupied by residues that have been noted in structural studies to contact DNA ( $\square$ ) or to participate in interactions within the core of the domain (O), as well as those that are highly conserved among all homeo domains $|O|$, are indicated below the sequence of the engrailed homeo domain as adapted from Laughon (1991). For ease of comparison with other homeo domain proteins, the amino acids are numbered according to the scheme of Qian et al. (1989). The POU homeo domain amino acid sequences have been compiled previously by Rosenfeld (1991). (B) Helical wheel representations of helices 1 and 2 of the Oct-1 POU homeo domain. The divergent amino acids are indicated in boldface type; the conserved amino acids are in outline type. The amino
elices into two halves, the lower of which is 
modimers in a manner similar or identical to that of the wild-type protein (data not shown). Several amino acid substitutions significantly reduced the ability of the Oct-1 POU homeo domain to form a $\mathrm{Cl}$ complex. As illustrated in Figure 3, mutant proteins were incubated with $\alpha$ TIF and a chromatographic fraction of HeLa cell nuclear extract containing the $\mathrm{Cl}$ factor and assayed in an EMSA. For quantitative analysis, each protein was assayed for its ability to form a $\mathrm{Cl}$ complex at identical DNA-binding activity (Table 1). Substitution of lysine18 with glutamic acid (K18E) (Fig. 3, lane 8), serine-19 with cysteine (S19C) (lane 10), or glutamic acid-22 with alanine (E22A) (lane 14) in helix 1 or glutamic acid-30 with glutamine (E30Q) (lane 18) in helix 2 reduced the capacity of the Oct-1 POU homeo domain to form a $\mathrm{Cl}$ complex to that of $13 \%, 13 \%, 16 \%$, and $5 \%$ of wild type, respectively. In contrast to the substitution of serine-19 with cysteine, substitution of serine-19 with glycine (S19G) resulted in a protein with only a mildly reduced ability (81\% wild type) to form a $\mathrm{Cl}$ complex (lane 12 ). Oct-1 and Oct- 2 differ in the POU homeo domain at positions $12,14,22,32,33,36$, and 39 . Of these, only substitution of the Oct- 1 residue at position 22 with the corresponding Oct- 2 residue dramatically affected the ability of the protein to form a $\mathrm{Cl}$ complex (Fig. 3, cf. lanes 4, 6, 14, 20, 22, and 24; see Table 1). Stern et al. (1989) demonstrated previously that the simultaneous substitution of residues threonine-32, methionine-33, and aspartic acid-36 in the Oct-1 helix 2 with the corresponding residues from the Oct- 2 POU homeo domain reduced the efficiency of $\mathrm{C} 1$ complex formation. In this analysis the same combination of substitutions (T32L, M32L, D36E) had a relatively mild effect (68\% wild type) (Fig. 3, lane 26) compared with that which resulted from the aforementioned individual amino acid substitutions.

It is clear from these data that residues in both helices 1 and 2 of the Oct-1 POU homeo domain mediate protein-protein interactions that are required for the efficient assembly of the $\mathrm{Cl}$ complex. Among those amino acids that, when substituted, result in a polypeptide that is significantly disabled with respect to the formation of a $\mathrm{Cl}$ complex are those that are likely to be specifically and directly involved in the recognition of the Oct-1 POU homeo domain by the $\alpha$ TIF and Cl factors.

\section{Interaction of Oct-1 POU homeo domain variants with $\alpha T I F$}

The reduced ability of a mutant Oct-1 POU homeo domain protein to participate in the formation of a $\mathrm{Cl}$ complex could be the result of its diminished capacity to interact with $\alpha \mathrm{TIF}$, the $\mathrm{Cl}$ factor, or both. Although an Oct- $1 / \alpha$ TIF/DNA intermediate complex is not readily detected in a native gel EMSA, the cooperative DNAbinding interaction between the Oct-1 POU homeo domain and $\alpha$ TIF in the absence of the $\mathrm{Cl}$ factor can be detected in a UV-induced cross-linking assay (Kristie and Sharp 1990). Therefore, this assay was used to address whether the panel of mutant proteins could interact directly with $\alpha$ TIF. As illustrated in Figure 4, the wild-type

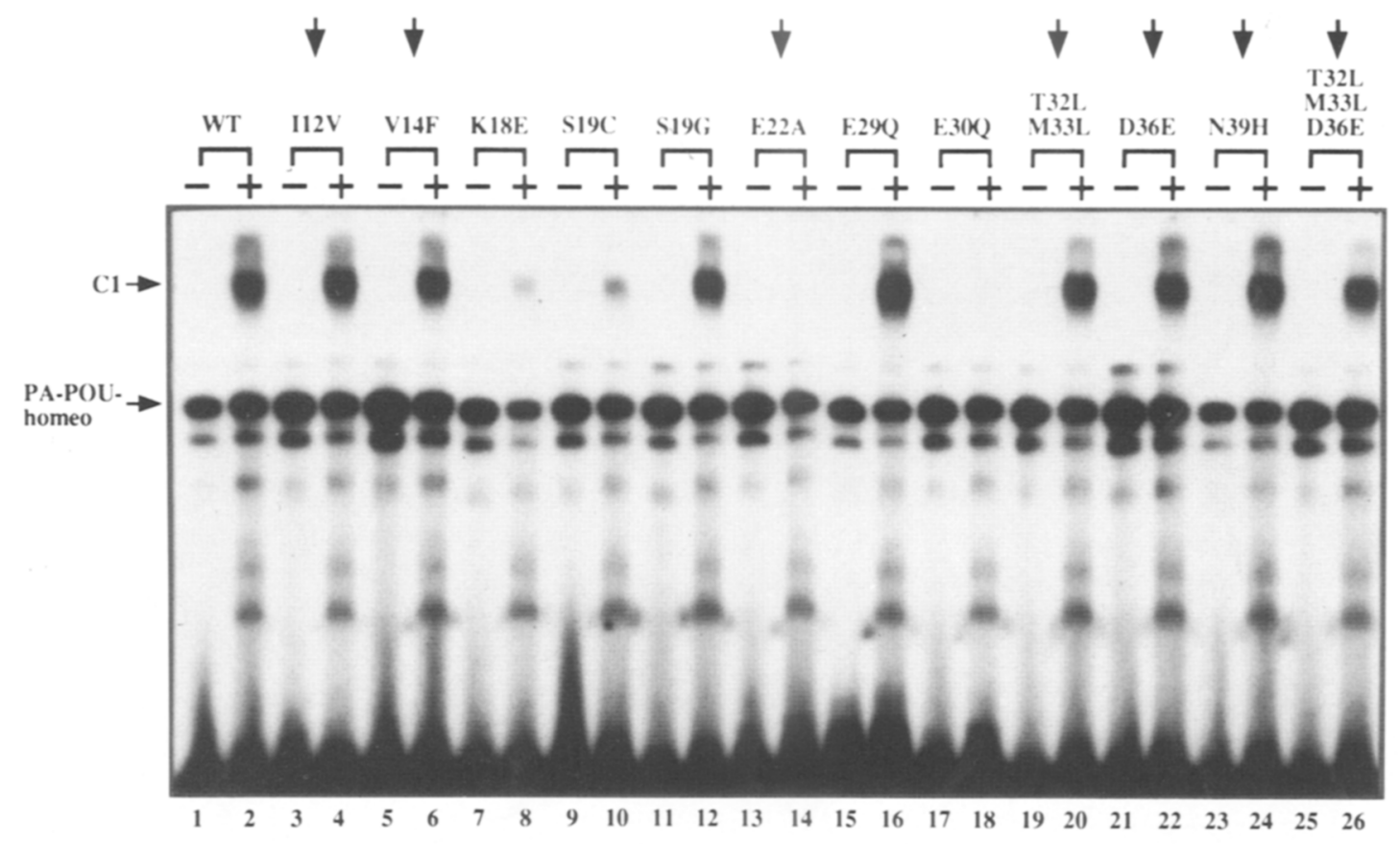

Figure 3. Effects of amino acid substitutions in helices 1 and 2 of the Oct-1 POU homeo domain on the formation of a $\mathrm{Cl}$ complex. Wild-type (WT) $(50 \mathrm{ng})$ and mutant PA-Oct-1 POU homeo domain fusion proteins (30-80 ng) were incubated in DNA-protein-binding reactions in the absence $(-)$ or presence $(+)$ of $15 \mathrm{ng}$ of PA- $\alpha$ TIF and $1 \mu \mathrm{l}$ of a chromatographic fraction containing the HeLa cell C1 factor as indicated. The positions of the $\mathrm{Cl}$ and homodimeric POU homeo domain-DNA complexes are indicated with horizontal arrows. Vertical arrows indicate the Oct-1 POU homeo domain variants in which the Oct-1 residues that differ from those of Oct-2 in the POU homeo domain have been substituted with the corresponding Oct- 2 amino acids. 
Table 1. Phenotypes associated with amino acid substitutions in the Oct-1 POU homeo domain

\begin{tabular}{|c|c|c|c|}
\hline & Substitution & $\begin{array}{l}\text { Ability to } \\
\text { form Cl } \\
(\% \mathrm{wt})^{\mathrm{a}}\end{array}$ & $\begin{array}{l}\text { Ability to } \\
\text { interact } \\
\text { with } \alpha \mathrm{TIF}\end{array}$ \\
\hline \multirow[t]{12}{*}{ Helix 1} & $\mathrm{~N} 11 \rightarrow \mathrm{G} 11$ & 123 & + \\
\hline & $\mathrm{N} 11 \rightarrow \mathrm{A} 11$ & 108 & + \\
\hline & $\mathrm{I} 12 \rightarrow \mathrm{V} 12$ & 109 & + \\
\hline & $\mathrm{I} 12 \rightarrow \mathrm{G} 12$ & 92 & + \\
\hline & $\mathrm{V} 14 \rightarrow \mathrm{Gl} 4$ & 114 & + \\
\hline & $\mathrm{V} 14 \rightarrow \mathrm{F} 14$ & 89 & + \\
\hline & A15 $\rightarrow$ G15 & 75 & + \\
\hline & $\mathrm{K} 18 \rightarrow \mathrm{E} 18$ & 13 & - \\
\hline & $\mathrm{S} 19 \rightarrow \mathrm{G} 19$ & 81 & + \\
\hline & $\mathrm{S} 19 \rightarrow \mathrm{C} 19$ & 13 & - \\
\hline & L21 $\rightarrow$ G21 & 99 & + \\
\hline & $\mathrm{E} 22 \rightarrow \mathrm{A} 22$ & 16 & - \\
\hline \multirow[t]{13}{*}{ Helix 2} & E29 $\rightarrow$ Q29 & 101 & + \\
\hline & $\mathrm{E} 30 \rightarrow \mathrm{Q} 30$ & 5 & - \\
\hline & T32M33 $\rightarrow$ L32L33 & 77 & $+1-$ \\
\hline & $\mathrm{T} 32 \mathrm{M} 33 \rightarrow \mathrm{V} 32 \mathrm{~V} 33$ & 34 & - \\
\hline & T32M33 $\rightarrow$ L32V33 & 39 & - \\
\hline & D36 $\rightarrow$ E36 & 95 & + \\
\hline & $\mathrm{Q} 37 \rightarrow \mathrm{E} 37$ & 108 & + \\
\hline & $\mathrm{Q} 37 \rightarrow \mathrm{A} 37$ & 105 & + \\
\hline & $\mathrm{N} 39 \rightarrow \mathrm{H} 39$ & 98 & + \\
\hline & $\mathrm{N} 39 \rightarrow \mathrm{D} 39$ & 145 & + \\
\hline & $\mathrm{N} 39 \rightarrow \mathrm{Y} 39$ & 113 & + \\
\hline & T32M33D36 $\rightarrow$ L32L33E36 & 68 & $+1-$ \\
\hline & S28T32M33 $\rightarrow$ L28L32L33 & 73 & $+1-$ \\
\hline
\end{tabular}

aPA-Oct-1 POU homeo domain fusion proteins were incubated in DNA-protein-binding reactions with subsaturating amounts of PA- $\alpha$ TIF and $\mathrm{Cl}$ factor as described in Materials and methods and in the legend to Fig. 3. The amount of $\mathrm{Cl}$ complex formed with each mutant protein was compared with that formed with the wild type (wt) at equivalent DNA-binding activity in reactions in which $0.1-1.0 \%$ of the probe was bound by POU homeo domain homodimer. In all cases, the concentration of mutant protein that was required to achieve equivalent DNA binding to that of the wild-type protein did not vary by more than twofold of the wild-type protein concentration. The numbers correspond to the average of at least three experiments for each mutant. The substitutions are grouped according to location in helices 1 and 2. Substitutions that were made in the intervening loop reduced the apparent DNA-binding affinity of the domain and were therefore not pursued.

bPA-Oct-1 POU homeo domain fusion proteins were incubated in DNA-protein-binding and UV-cross-linking reactions as described in Materials and methods and in the legend to Fig. $4.1+1$ The Oct-1 POU homeo domain variant stimulated the efficiency of UV-cross-linking of PA- $\alpha$ TIF to DNA by 4- to 6-fold or to a level equivalent to that observed with the wild-type protein; $1+1-12$ - to 3 -fold stimulation; $1-1<1.5$-fold stimulation.

Oct-1 POU homeo domain stimulated the efficiency of UV cross-linking of $\alpha$ TIF to the $\alpha /$ IE element by four- to fivefold as compared with reactions containing only the $\alpha$ TIF protein (cf. lanes 2 and 3). Interestingly, each of the mutant proteins that contained amino acid substitutions that significantly reduced the ability of the protein to form a $\mathrm{Cl}$ complex also failed to stimulate the cross- linking of $\alpha$ TIF to DNA (lanes $6,7,9,11$ ). The mutant proteins that exhibited relatively milder phenotypes with respect to their assembly into $\mathrm{Cl}$ complexes also exhibited diminished capacities to stimulate the cooperative DNA binding of $\alpha$ TIF (Table 1). Conversely, those Oct-1 POU homeo domain variants that exhibited nearly wildtype phenotypes in a $\mathrm{Cl}$ complex formation assay also retained the ability to stimulate the cross-linking of $\alpha$ TIF (e.g., Fig. 4, lanes 4,5,8,10,12,13; Table 1). Thus, the phenotype exhibited by all mutants that were deficient in the assembly of a $\mathrm{Cl}$ complex can be accounted for by their decreased abilities to interact specifically with the viral $\alpha$ TIF factor.

\section{A single amino acid substitution in the Oct-2 POU homeo domain confers the ability to participate efficiently in the formation of a C1 complex and to stimulate the cooperative $D N A$ binding of $\alpha$ TIF}

Figure 5 depicts the surface of the Oct-1 POU homeo domain which should be accessible for protein-protein interactions. The arrows denote residues $18,19,22$, and 30 , which, when substituted individually, resulted in mutant proteins with significantly reduced potential to form the $\mathrm{Cl}$ complex and to interact cooperatively with $\alpha$ TIF. These residues are thus expected to be involved in the critical interactions of the Oct-1 POU homeo do-

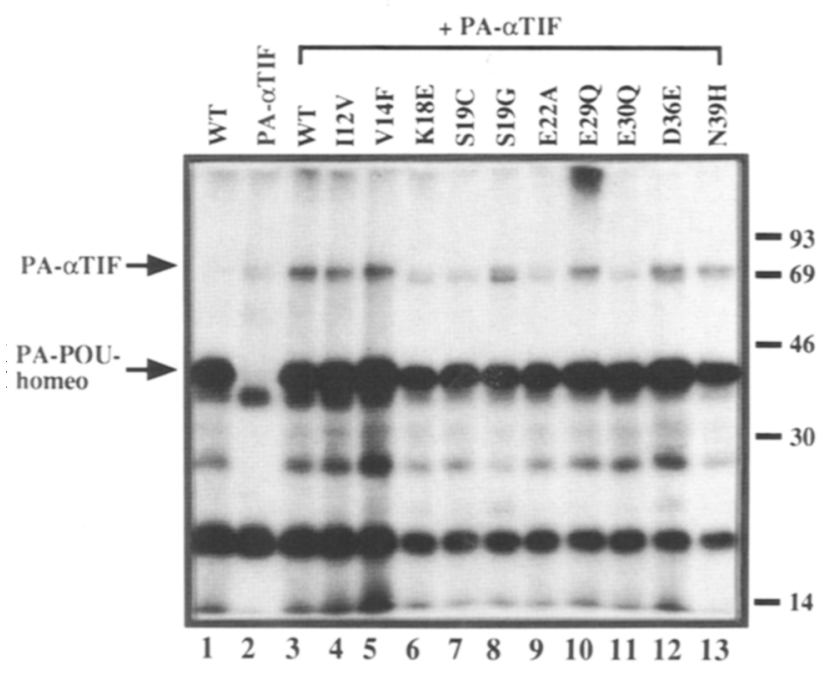

Figure 4. Cooperative interactions of $\alpha$ TIF with variants of the Oct-1 POU homeo domain. DNA-protein-binding and UV cross-linking reactions were done as described in Materials and methods. The reactions contained $1100 \mathrm{ng}$ of SDS-PAGE-purified PA- $\alpha$ TIF and $500 \mathrm{ng}$ of wild-type (WT) or mutant PA-Oct-1 POU homeo domain fusion proteins as indicated. The positions of PA- $\alpha$ TIF $(74 \mathrm{kD})$ and the PA-Oct-1 POU homeo domain (38 $\mathrm{kD}$ ) proteins are indicated with arrows. The $27-\mathrm{kD}$ species is a degradation product of the PA-Oct-1 POU homeo domain proteins. The bands at 17 and $36 \mathrm{kD}$ are present in control reactions in the absence of any PA fusion protein and are thus likely to be incompletely digested DNA. The migrations of ${ }^{14} \mathrm{C}$-labeled protein molecular mass markers are indicated at right. 


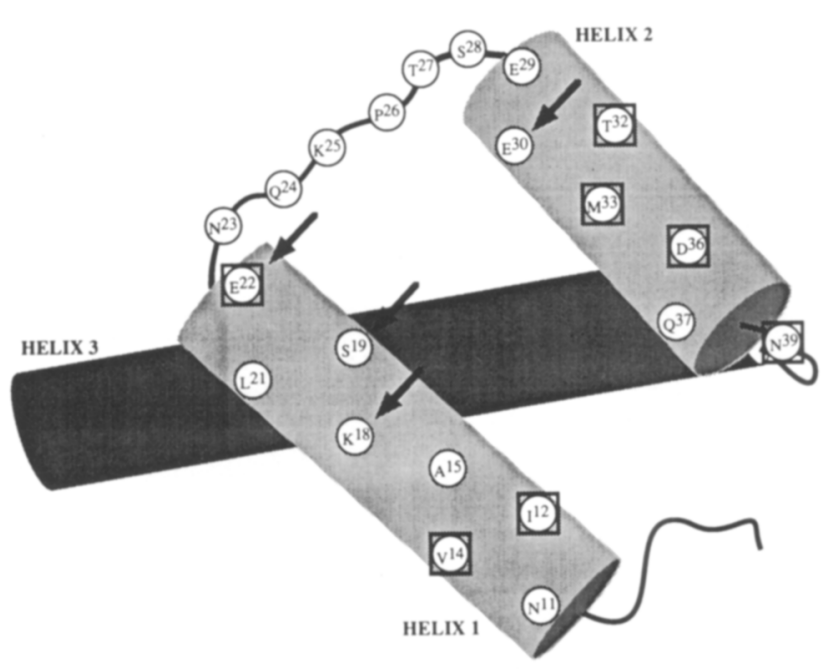

Figure 5. The surface of the Oct-1 POU homeo domain which is specifically recognized in the assembly of the $\mathrm{Cl}$ complex. The Oct-1 POU homeo domain was modeled according to the crystal structure of the engrailed homeo domain-DNA complex (Kissinger et al. 1990). The displayed amino acids are expected to occupy positions in helices 1 and 2 and the intervening loop, which are on the surface of the domain that is opposite the DNA-binding surface. The residues which, when substituted, resulted in the most pronounced reductions in the ability to form the $\mathrm{Cl}$ complex and stimulate the cooperative DNA binding of $\alpha$ TIF are indicated with arrows. The amino acids that differ between Oct-1 and Oct- 2 in the POU homeo domain are boxed.

main with $\alpha$ TIF in the assembly of a $\mathrm{Cl}$ complex. The amino acids that differ between the Oct-1 and Oct-2 POU homeo domains are indicated by boxes.

Of the 7 amino acid differences between Oct-1 and Oct-2 in the POU homeo domain, substitution of the glutamic acid at position 22 in Oct-1 for the corresponding alanine in Oct- 2 produced a protein that displayed the most significant phenotype. This suggested that the amino acid at this position would not only be a key determinant for the recognition of Oct-l in the formation of a $\mathrm{Cl}$ complex but also one that might account for the significantly lower affinity of the Oct- 2 POU homeo domain for components of the $\mathrm{Cl}$ complex. Therefore, a variant of the Oct-2 POU homeo domain was produced that contained a substitution of the Oct- 2 alanine at position 22 with the Oct-1 glutamic acid. As shown in Figure 6A, this single substitution now confers upon the Oct-2 POU homeo domain the ability to interact efficiently with components of the $\mathrm{Cl}$ complex (cf. lanes 2 and 4). This Oct- 2 variant bound to the $\alpha /$ IE element as a monomeric protein with an affinity that was comparable to that of the wild-type Oct-2 POU homeo domain (lanes 1,3; data not shown). On the basis of the results obtained with the Oct-1 variants, it was expected that the enhanced capacity of this protein to form a $\mathrm{Cl}$ complex would be concomitant with an increased ability to directly interact with $\alpha$ TIF. As shown in Figure 6B, the Oct-2 POU homeo domain variant does, in fact, have an increased ability to stimulate the binding of $\alpha$ TIF to DNA in the UV-induced cross-linking assay as compared with the wild-type Oct-2 POU homeo domain protein (cf. lanes 2 and 3).

\section{Discussion}

Although it is clear that homeo domain proteins are critical for many highly regulated processes, the mechanisms by which these proteins act with exquisite functional specificity have been largely undefined. The functions of homeo domain proteins have been investigated most extensively in Drosophila morphogenesis, in which the regulatory specificity of several proteins has been mapped to a minimal region containing the homeo domain (Kuziora and McGinnis 1989; Gibson et al. 1990; Malicki et al. 1990; Mann and Hogness 1990; McGinnis et al. 1990; Furukubo-Tokunaga et al. 1992; Lin and McGinnis 1992). This specificity cannot be explained

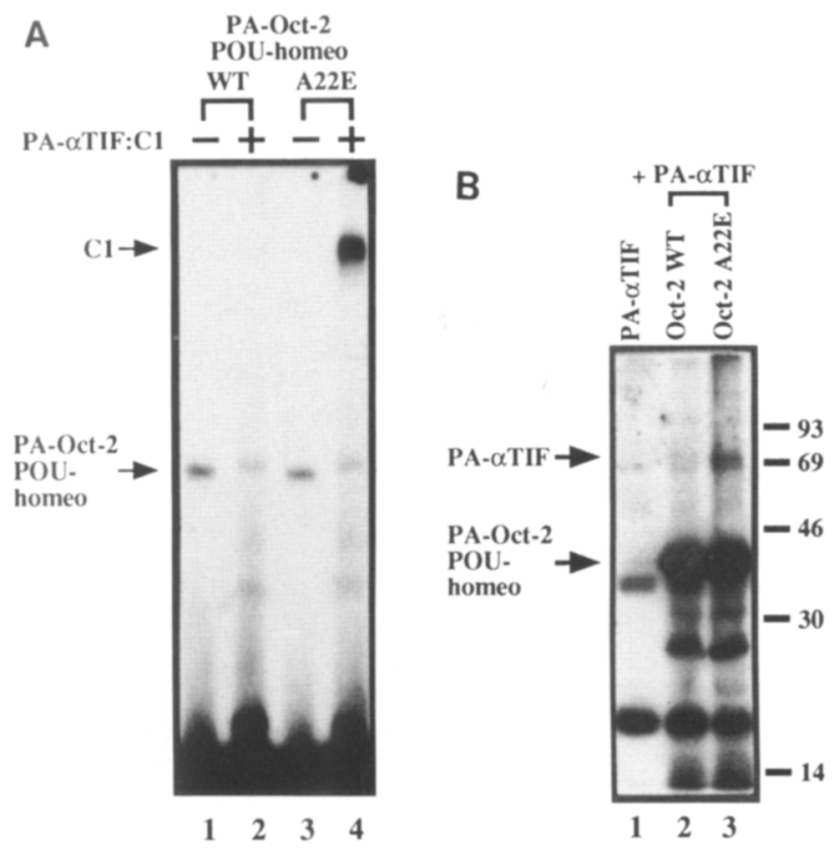

Figure 6. The substitution of alanine- 22 with glutamic acid in the Oct-2 POU homeo domain enhances the ability of the protein to form a $\mathrm{Cl}$ complex and interact with $\alpha$ TIF. $(A)$ The wild-type (WT) PA-Oct-2 POU homeo domain ( $50 \mathrm{ng}$ ) or a mutant containing the substitution of alanine- 22 with glutamic acid (A22E) (50 ng) was incubated in DNA-protein-binding reactions in the absence $(-)$ or presence $(+)$ of $15 \mathrm{ng}$ of PA- $\alpha$ TIF and $1 \mu l$ of a chromatographic fraction containing the HeLa cell $\mathrm{Cl}$ factor as indicated. The positions of the $\mathrm{Cl}$ and monomeric Oct-2 POU homeo domain-DNA complexes are indicated with arrows. $(B)$ DNA-protein-binding and UV cross-linking reactions were done using $930 \mathrm{ng}$ of SDS-PAGE-purified PA- $\alpha$ TIF, alone or in the presence of $500 \mathrm{ng}$ of either the wild-type (WT) PA-Oct-2 POU homeo domain or the A22E mutant. The positions of PA- $\alpha$ TIF $(74 \mathrm{kD})$ and the PA-Oct-2 POU homeo domain $(38 \mathrm{kD})$ are indicated with arrows. The migrations of ${ }^{14} \mathrm{C}$ labeled protein molecular mass markers are indicated at right. 
solely by the DNA-binding properties of these homeo domains because proteins with distinct biological actions exhibit extremely similar DNA sequence specificities. We propose that the biological specificity contained in the homeo domain can be determined primarily by the recognition of the surface of the DNA-bound domain by other proteins. This is clearly the mechanism by which Oct-1 is selectively assembled into the regulatory $\mathrm{Cl}$ complex on the $\alpha /$ immediate-early enhancer of the HSV. The recognition of Oct-1 is mediated principally by specific interactions between the viral $\alpha$ TIF factor and amino acid residues on the surface of helices 1 and 2 of the Oct-1 POU homeo domain.

\section{Amino acid residues in helices 1 and 2 of the Oct-1 POU homeo domain are critical for the assembly of the C1 complex}

A panel of variants of the Oct-1 POU homeo domain was generated by site-directed mutagenesis. To preserve the structure of the Oct-1 POU homeo domain and its ability to bind DNA, the mutagenesis was limited to those amino acids that are divergent and are predicted to occupy positions on the surface of the domain. In most cases, the character of an individual side chain residue was radically changed by the substitution; therefore, a mutation that did not result in a dramatic phenotype indicates that the wild-type residue at that position is unlikely to mediate a critical interaction. Conversely, a mutation that did result in a pronounced phenotype indicates that the wild-type residue is either interacting directly with components of the $\mathrm{Cl}$ complex or is sterically constrained in the assembled complex. Specifically, the individual substitution of lysine-18, serine-19, glutamic acid-22, and glutamic acid-30 resulted in the most dramatic reductions in the ability of the Oct-1 POU homeo domain to participate in the formation of a $\mathrm{Cl}$ complex. Although lysine-18 may be specifically recognized in the $\mathrm{Cl}$ complex, the phenotype may also result from a charge or steric incompatibility of the glutamic acid introduced at that position. Serine-19 is unlikely to mediate a direct, specific interaction because only mild effects were observed upon substitution of this residue with glycine. However, a more dramatic phenotype resulted from the substitution of this residue with cysteine, which represents the replacement of a hydroxyl group with a sulfhydryl group. This suggests that the side chain of this residue is sterically constrained in the assembled complex. The result of the replacement of glutamic acid-30 with glutamine indicates that this residue is in intimate proximity to and may mediate a direct contact with components of the $\mathrm{Cl}$ complex. Finally, it is likely that glutamic acid-22 is recognized specifically in the $\mathrm{Cl}$ complex by a direct interaction because the removal of much of its side chain (substitution with alanine) resulted in a significant phenotype. More significantly, the replacement of alanine with glutamic acid at position 22 in the Oct- 2 POU homeo domain resulted in a variant with a dramatically enhanced ability to form a $\mathrm{Cl}$ complex.
Recognition of the Oct-1 POU homeo domain by $\alpha T I F$

Each amino acid substitution that compromised the formation of the $\mathrm{Cl}$ complex also reduced the ability of the Oct-1 POU homeo domain to stimulate cooperatively the binding of $\alpha$ TIF to DNA, indicating that the surface of the Oct-1 POU homeo domain is principally recognized by the viral $\alpha$ TIF protein. To date, the specific role of the $\mathrm{Cl}$ factor in the stabilization of the $\mathrm{Cl}$ complex is unclear. This multicomponent factor binds to $\alpha \mathrm{TIF}$ in the absence of DNA or Oct-1 (Kristie and Sharp 1990). A related activity is also present in insect cells (Kristie et al. 1989), suggesting that the $\mathrm{Cl}$ factor is evolutionarily conserved.

The importance of glutamic acid at position 22 in helix 1 of the Oct-1 POU homeo domain

Stern et al. (1989) described a qualitative loss of the ability of the full Oct-1 protein to form a Cl complex when residues at positions 32,33 , and 36 in helix 2 were substituted simultaneously with the corresponding Oct-2 residues. The interpretation of these data was that helix 2 of the Oct-1 POU homeo domain contained critical determinants for the assembly of Oct- 1 into a $\mathrm{Cl}$ complex. In contrast, the equivalent construct in this analysis (T32L, M33L, D36E) exhibited only a mildly reduced ability (68\% wild type) to form the $\mathrm{Cl}$ complex. Other mutants that contained simultaneous substitutions of threonine- 32 and methionine- 33 had intermediate phenotypes in the $\mathrm{Cl}$ complex formation assay $134-77 \%$ wild type) and exhibited diminished abilities to stimulate the cross-linking of $\alpha$ TIF to DNA. However, the data presented here suggest that the most significant individual determinant for the discrimination between Oct-1 and Oct-2 lies not in helix 2 but in helix 1 at position 22 . Substitution of the glutamic acid in Oct-1 for the alanine in Oct- 2 produced an Oct-1 variant with a dramatically reduced ability to form a $\mathrm{Cl}$ complex and to interact with $\alpha$ TIF. The reciprocal exchange (Oct-2 A22E) resulted in an Oct-2 POU homeo domain protein with a significantly enhanced ability to form a Cl complex and to interact directly with $\alpha$ TIF. This strongly implicates the glutamic acid at position 22 as a critical determinant for the selective recognition of Oct- 1 in the formation of the $\mathrm{Cl}$ complex.

\section{Cooperative binding of the Oct-1 POU homeo domain}

In contrast to the intact Oct-1 POU domain, the Oct-1 POU homeo domain can bind the $\alpha /$ IE element cooperatively as a homodimer (Kristie and Sharp 1990). The difference in the abilities of the isolated Oct-1 and Oct-2 POU homeo domains to cooperatively form a homodimer on the $\alpha /$ IE element was surprising, but it is unlikely to be related to the respective capacities of the proteins to interact with other components in the formation of a $\mathrm{Cl}$ complex. The amino acid substitutions in Oct-1 that diminished its ability to form a $\mathrm{Cl}$ complex did not affect its potential to form a homodimer on the 
$\alpha /$ IE element. Conversely, the mutation in Oct-2 (A22E) that enhanced its capacity to form a $\mathrm{Cl}$ complex did not confer the ability to form a homodimer. The differences that account for the different potentials of the Oct-1 and Oct-2 POU homeo domains to homodimerize cooperatively are presently under investigation. The homodimerization of the Oct-1 protein may reflect unique capabilities of this protein for homeo domain-homeo domain interactions with other proteins. Consistent with this notion, Voss et al. (1991) have demonstrated that Oct- 1 and the pituitary-specific POU domain factor Pit-1 bind as a heterodimer to elements in the rat prolactin promoter and that the two proteins also associate in solution by an interaction mediated, in part, by the POU homeo domain of Pit-1. Of note, Treacy et al. (1992) have described the interesting regulatory consequences of the contrasting abilities of the Drosophila I-POU and twin of I-POU proteins to interact with the Cf1-a protein through POU homeo domain-POU homeo domain interactions.

\section{The interaction of Oct-1 and $\alpha$ TIF provides a model for the determination of homeo domain functional specificity by protein-protein interactions}

It is possible that the POU homeo domains of Oct-1 and Oct- 2 are recognized by cellular factors that are analogous to $\alpha$ TIF and serve to modulate their functional specificities. The existence of such factors would explain how the octamer element, which is recognized by both of these proteins, is important for the regulation of a wide variety of disparately controlled genes, including the constitutively expressed small nuclear RNA (snRNA) genes (Ares et al. 1987; Bark et al. 1987; Carbon et al. 1987; Murphy et al. 1987), the cell cycle-specifically expressed histone H2B gene (Sive et al. 1986; Fletcher et al. 1987; LaBella et al. 1988), and the tissuespecifically expressed interleukin-2 (Ullman et al. 1991) and immunoglobulin genes (Mizushima-Sugano and Roeder 1986; Staudt et al. 1986; Gerster et al. 1987; Scheidereit et al. 1987; Wirth et al. 1987; LeBowitz et al. 1988; Muller et al. 1988).

It is likely that the recognition of the homeo domain surface by other proteins is a common mechanism by which the regulatory specificities of this family of factors are determined. In Drosophila, where the developmental regulatory potential of a particular factor can be readily assayed, minimal amino acid differences between two homeo domains can determine the distinct biological actions of the proteins (Lin and McGinnis 1992). The observation that this biological specificity may not be related to DNA-binding specificity is readily explained by a model based on the recognition of the surface of the homeo domain such as that proposed here for the Oct-1 POU homeo domain. In this system, the four critical residues for $\mathrm{Cl}$ complex formation are clustered in the carboxy-terminal half of helix 1 and the amno-terminal third of helix 2. Therefore, this surface of the Oct-1 POU homeo domain must be exposed to components of the $\mathrm{Cl}$ complex when the Oct-1 protein binds DNA in vivo. This spatial architecture is probably a general feature of homeo domain proteins: The surface of the domain is exposed in the protein-DNA complex, providing a target for regulatory proteins that contribute to homeo domain functional specificity.

\section{Materials and methods \\ Mutagenesis and production of PA fusion proteins}

Constructs encoding the $S$. aureus protein A fusion proteins that contained the Oct-1 POU domain [amino acids 270-441 (Sturm et al. 1988)] and $\alpha$ TIF [amino acids $1-412$ (Pellett et al. 1985)] have been described (Kristie and Sharp 1990). Plasmid pOIHSS was constructed by cloning the DNA fragment encoding the Oct-1 POU homeo domain (amino acids 368-441) into the vector $\mathrm{pBS}(+)$ (Stratagene) using the $E$. coli TGl strain. The resultant transformant was grown with $\mathrm{R} 408$ helper phage (Stratagene) at $37^{\circ} \mathrm{C}$ for $18 \mathrm{hr}$. Single-stranded DNA was isolated from the culture supernatant after the addition of 0.25 volume of $20 \% \mathrm{PEG}(8000) / 3.5 \mathrm{M} \mathrm{NH}_{4} \mathrm{Ac}$, incubation at $4^{\circ} \mathrm{C}$ for $30 \mathrm{~min}$, and centrifugation at $10,000 \mathrm{~g}$ for $20 \mathrm{~min}$. The single-stranded DNA pellet was extracted five times with phenol-chloroform [1:1 ( $\mathrm{vol} / \mathrm{vol})]$, precipitated with ethanol, and resuspended for use as a substrate for mutagenesis. Mutagenesis was performed using the oligonucleotide-directed in vitro mutagenesis system version 2 (Amersham) according to the manufacturer's instructions. Oligonucleotides used for the mutagenesis were from 20 to 30 nucleotides long and contained $\sim 10$ nucleotides on each side of the mutation-specific bases. The products of the mutagenesis reactions were screened by dideoxynucleotide sequencing. The fragments that contained the desired mutations were isolated and cloned into pRIT2T (Pharmacia) so as to generate in-frame fusions with the PA gene. Plasmid pO2HWT was constructed by cloning the DNA fragment encoding the Oct- 2 POU homeo domain [amino acids 286-356 (Clerc et al. 1988)] into pRIT2T so as to generate an in-frame fusion with the PA gene. pO2HA317E, a construct encoding the Oct-2 POU homeo domain mutant (alanine-317 to glutamic acid) was generated by making a base substitution via recombinant PCR (Higuchi 1990). The sequences of both Oct- 2 constructs were verified by dideoxynucleotide sequencing. Protein A fusion proteins were expressed in E. coli $\mathrm{N} 4830$ strain and were purified by affinity chromatography on IgG-Sepharose (Pharmacia) as described previously (Kristie and Sharp 1990). The concentration and purity of each PA fusion protein were determined by densitometric analysis of Coomassie-stained SDS-PAGE-resolved proteins. The fusion proteins were judged to be $30-90 \%$ pure.

\section{EMSAS}

The HSV $\alpha 0$ probe $\mid \alpha /$ IE element: 5'-GTGCATGCTAATGATATTCTTTGGGG) used in the C1 complex formation assays has been described previously (Kristie and Sharp 1990). DNA-protein-binding reactions contained $0.4-0.8 \mathrm{ng}$ of DNA probe, $300 \mathrm{ng}$ of poly[d(I-C)]/poly[d(I-C)], $10 \mathrm{~mm}$ HEPES (pH 7.9), $0.5 \mathrm{~mm}$ EDTA, 30-90 mM KCl, $0.75 \mathrm{~mm}$ DTT, 4\% Ficoll-400, $300 \mu \mathrm{g} / \mathrm{ml}$ of bovine serum albumin, and the appropriate purified proteins or chromatographic fraction in a total volume of 10 $\mu l$. Reactions were incubated at $30^{\circ} \mathrm{C}$ for $30 \mathrm{~min}$ and resolved in $4 \%$ nondenaturing polyacrylamide gels using $0.5 \times$ Tris-glycine electrophoresis buffer as described previously (Fried and Crothers 1981; Garner and Revzin 1981). Chromatographic fractions that contained the $\mathrm{Cl}$ factor were prepared by fractionation of a nuclear extract of HeLa cells (Dignam et al. 1983). The extract was applied to a Mono S FPLC column in buffer A plus 
$100 \mathrm{~mm} \mathrm{KCl}$ [40 mM HEPES (pH 7.9); $0.5 \mathrm{~mm}$ EDTA, $0.5 \mathrm{~mm}$ DTT; $20 \%$ (vol/vol) glycerol]. The column was washed with 10 column volumes of buffer A plus $100 \mathrm{mM} \mathrm{KCl}$, and the adsorbed proteins were eluted in buffer A with a linear gradient of 100 $700 \mathrm{mM} \mathrm{KCl}$. Fractions that contained the $\mathrm{Cl}$ factor activity were applied to a Mono Q FPLC column in buffer A plus $50 \mathrm{~mm}$ $\mathrm{KCl}$. The column was washed with 10 column volumes of buffer A plus $50 \mathrm{~mm} \mathrm{KCl}$, and the adsorbed proteins were eluted in buffer A with a linear gradient of $50-700 \mathrm{mM} \mathrm{KCl}$. The fractions that contained the $\mathrm{Cl}$ factor activity were combined, and aliqouts were incubated with potato acid phosphatase (Sigma) for $15 \mathrm{~min}$ at $25^{\circ} \mathrm{C}$ before addition to protein-DNA-binding reactions. To compare DNA-binding affinities, wild-type and mutant PA-POU homeo domain proteins were titrated into DNAprotein-binding reactions that were performed under the conditions described above using a probe containing a consensus octamer site (5'-ATGCAAAT-3') (Kristie and Sharp 1990), $30 \mathrm{ng}$ of poly[d(I-C)]/poly[d(I-C)] and between 5 and 500 ng of octamerbinding protein. The protein-DNA complexes and the free DNA were quantitated after electrophoresis using a PhosphorImager (Molecular Dynamics) with ImageQuant 3.0 and 3.15 software.

\section{UV-induced cross-linking reactions}

Body-labeled DNA probes were prepared as described previously (Kristie and Sharp 1990). The DNA-protein-binding reactions were performed under the conditions described above and contained 40-150 ng of poly[d(I-C)]/poly[d(I-C)], 200-500 ng of PAPOU homeo domain protein, and $200-1100$ ng of PA- $\alpha$ TIF. Reactions were incubated at $30^{\circ} \mathrm{C}$ for $30 \mathrm{~min}$ and were irradiated with a Fotodyne UV lamp $(254 \mathrm{~nm})$ at $3000 \mu \mathrm{W} / \mathrm{cm}^{2}$ in a $15^{\circ} \mathrm{C}$ water bath. The reactions were brought to $7.5 \mathrm{mM} \mathrm{CaCl}_{2}$ and digested with $10 \mu \mathrm{g}$ of DNase 1 and 5 units of micrococcal nuclease for $30 \mathrm{~min}$ at $37^{\circ} \mathrm{C}$. The digested products were resolved in an $11 \%$ SDS-denaturing gel and transferred to nitrocellulose in the presence of $0.1 \%$ SDS. The PA- $\alpha$ TIF used in these reactions was purified by preparative SDS-PAGE as described previously (Kristie and Sharp 1990). The amount of cross-linking of $\alpha$ TIF to DNA was quantitated using a PhosphorImager (Molecular Dynamics) with ImageQuant 3.15 software.

\section{Acknowledgments}

We thank A. Gil, D. Chasman, P. McCaw, L. Johnson, R. Meyers, and C. Pabo for provocative discussions and critical review of this manuscript; $M$. Siafaca for her ever present assistance $;$. Parent and C. Wrenn for indispensable technical assistance; and members of the Sharp laboratory for their continual support. J.L.P. is supported by the Harvard Medical School M.D.-Ph.D. program by U.S. Public Health Service National Research Service Award 2 T32 GM07753-13 and by the Massachusetts Institute of Technology Department of Biology. T.M.K. is a Leukemia Society of America Special Fellow. This work was supported by U.S. Public Health Service grant PO1-CA42063 from the National Institutes of Health, by cooperative agreement CDR-8803014 from the National Science Foundation to P.A.S., and partially by National Cancer Institute Cancer Center Support (core) grant P30-CA14051.

The publication costs of this article were defrayed in part by payment of page charges. This article must therefore be hereby marked "advertisement" in accordance with 18 USC section 1734 solely to indicate this fact.

\section{Note added in proof}

We note that J.-S. Lai, M.A. Cleary, and W. Herr have made similar observations regarding the significance of E22 in helix 1 of the Oct-1 homeo domain in its interaction with $\alpha$ TIF /Lai et al., this issue).

\section{References}

Affolter, M., A. Schier, and W.J. Gehring. 1990. Homeodomain proteins and the regulation of gene expression. Curr. Opin. Cell Biol. 2: 485-495.

Ares, M. Jr., J. Chung, L. Giglio, and A.M. Weiner. 1987. Distinct factors with SP1 and NFA specificities bind to adjacent functional elements of the human U2 snRNA gene enhancer. Genes \& Dev. 1: 808-817.

Bark, C., P. Weller, J. Zabeilski, L. Janson, and U. Petterson. 1987. A distant enhancer element is required for transcription of a U6 RNA gene. Nature 328: 356-362.

Bzik, D.J. and C.M. Preston. 1986. Analysis of DNA sequences which regulate the transcription of herpes simplex virus immediate early gene 3: DNA sequences required for enhancerlike activity and response to trans-activation by a virion polypeptide. Nucleic Acid Res. 14: 929-943.

Carbon, P., S. Murgo, J.-P. Ebel, A. Krol, G. Tebb, and I.W. Mattaj. 1987. A common octamer motif binding protein is involved in the transcription of the U6 snRNA by RNA polymerase III and U2 snRNA by RNA polymerase II. Cell 51: 71-79.

Clerc, R.G., L.M. Corcoran, J.H. LeBowitz, D. Baltimore, and P.A. Sharp. 1988. The B-cell-specific Oct-2 protein contains POU box- and homeo box-type domains. Genes \& Dev. 2: $1570-1581$.

Dignam, J.D., R.M. Lebovitz, and R. Roeder. 1983. Accurate transcription initiation by RNA polymerase II in a soluble extract from isolated mammalian nuclei. Nucleic Acids Res. 11: $1475-1489$.

Fletcher, C., N. Heintz, and R.G. Roeder. 1987. Purification and characterization of OTF-1, a transcription factor regulating cell cycle expression of a human histone $\mathrm{H} 2 \mathrm{~b}$ gene. Cell 51: 773-781.

Fried, M. and D. Crothers. 1981. Equilibria and kinetics of lac repressor-operator interactions by polyacrylamide gel electrophoresis. Nucleic Acids Res. 9: 6505-6525.

Furukubo-Tokunaga, K., M. Muller, M. Affolter, L. Pick, U. Kloter, and W.J. Gehring. 1992. In vivo analysis of the helixturn-helix motif of the fushi tarazu homeo domain of Drosophila melanogaster. Genes \&) Dev. 6: 1082-1096.

Gaffney, D.F., J. McLauchlan, J.L. Whitton, and J.B. Clements. 1985. A modular system for the assay of transcription regulatory signals: The sequence TAATGARAT is required for herpes simplex virus immediate early gene activation. $\mathrm{Nu}$ cleic Acids Res. 13: 7847-7862.

Garner, M.N. and A. Revzin. 1981. A gel electrophoresis method for quantifying the binding of proteins to specific DNA regions. Nucleic Acids Res. 9: 3047-3060.

Gehring, W.J. 1987. Homeo boxes in the study of development. Science 236: 1245-1252.

Gerster, T. and R.G. Roeder. 1988. A herpesvirus trans-acting protein interacts with transcription factor OTF-1 and other cellular proteins. Proc. Natl. Acad. Sci. 85: 6347-6351.

Gerster, T., P. Matthias, M. Thali, J. Jiricny, and W. Schaffner. 1987. Cell type-specificity elements of the immunoglobulin heavy chain gene enhancer. EMBO J. 6: 1323-1330.

Gibson, G., A. Schier, P. LeMotte, and W.J. Gehring. 1990. The specificities of sex combs reduced and antennapedia are defined by a distinct portion of each protein that includes the homeodomain. Cell 62: 1087-1103. 
Hayashi, S. and M.P. Scott. 1990. What determines the specificity of action of Drosophila homeodomain proteins? Cell 63: $883-894$.

He, X., M.N. Treacy, D.M. Simmons, H.A. Ingraham, L.W. Swanson, and M.G. Rosenfeld. 1989. Expression of a large family of POU-domain regulatory genes in mammalian brain development. Nature 340: 35-42.

Herr, W., R.A. Sturm, R.G. Clerc, L.M. Corcoran, D. Baltimore, P.A. Sharp, H.A. Ingraham, M.G. Rosenfeld, M. Finney, G. Ruvkin, and H.R. Horvitz. 1988. The POU domain: A large conserved region in the mammalian pit-1, oct-1, oct-2, and Caenorhabditis elegans unc-86 gene products. Genes 4$)$ Dev. 2: 1513-1516.

Higuchi, R. 1990. Recombinant PCR. In PCR protocols: $A$ guide to methods and applications (ed. M.A. Innis, D.H. Gelfand, J.J. Sninsky, and T.J. White), pp. 177-183. Academic Press, Inc., San Diego, CA.

Kissinger, C.R., B. Liu, E. Martin-Blanco, T.B. Kornberg, and C.O. Pabo. 1990. Crystal structure of an engrailed homeodomain-DNA complex at 2.8 A resolution: A framework for understanding homeodomain-DNA interactions. Cell 63: $579-590$.

Kristie, T.M. and B. Roizman. 1984. Separation of sequences defining basal expression from those conferring alpha gene recognition within the regulatory domains of herpes simplex virus 1 alpha genes. Proc. Natl. Acad. Sci. 81: 4065-4069.

Kristie, T.M. and P.A. Sharp. 1990. Interactions of the Oct-1 POU subdomains with specific DNA sequences and with the HSV $\alpha$-trans-activator protein. Genes \& Dev. 4: 23832396.

Kristie, T.M., J.H. LeBowitz, and P.A. Sharp. 1989. The octamerbinding proteins form multi-protein-DNA complexes with the HSV alpha TIF regulatory protein. $E M B O ~ J .8: 4229$ 4238.

Kuziora, M.A. and W. McGinnis. 1989. A homeodomain substitution changes the regulatory specificity of the deformed protein in Drosophila embryos. Cell 59: 563-571.

La Bella, F., H.L. Sive, R.G. Roeder, and N. Heintz. 1988. Cellcycle regulation of a human histone $\mathrm{H} 2 \mathrm{~b}$ gene is mediated by the H2b subtype-specific consensus element. Genes $\Leftrightarrow$ Dev. 2: 32-39.

Laughon, A. 1991. DNA binding specificity of homeodomains. Biochemistry 30: 11357-11367.

LeBowitz, J.H., T. Kobayashi, L. Staudt, D. Baltimore, and P.A. Sharp. 1988. Octamer-binding protein from B or HeLa cells stimulate transcription of the immunoglobulin heavy-chain promoter in vitro. Genes \&) Dev. 2: 1227-1237.

Lin, L. and W. McGinnis. 1992. Mapping functional specificity in the Dfd and Ubx homeo domains. Genes \& Dev. 6: 10711081.

Mackem, S. and B. Roizman. 1982a. Regulation of alpha genes of herpes simplex vinus: The alpha 27 promoter-thymidine kinase chimeric gene is positively regulated in converted $\mathrm{L}$ cells. I. Virol. 43: 1015-1023.

- 1982b. Structural features of the alpha gene 4, 0, and 27 promoter-regulatory sequences which confer alpha regulation on chimeric thymidine kinase genes. J. Virol. 44: 939949.

-1982c. Differentiation between alpha promoter and regulator regions of herpes simplex virus I: The functional domains and sequence of a movable alpha regulator. Proc. Natl. Acad. Sci. 79: 4917-4921.

Malicki, J., K. Schughart, and W. McGinnis. 1990. Mouse Hox2.2 specifies thoracic segmental identity in Drosophila embryos and larvae. Cell 63: 961-967.

Mann, R.S. and D.S. Hogness. 1990. Functional dissection of ultrabithorax proteins in D. melanogaster. Cell 60: 597-610.

McGinnis, N., M.A. Kuziora, and W. McGinnis. 1990. Human Hox -4.2 and Drosophila deformed encode similar regulatory specificities in Drosophila embryos and larvae. Cell 63: 969976.

McKnight, J.L.C., T.M. Kristie, S. Silver, P.E. Pellett, G. Mavromara-Nazos, G. Campadelli-Fiume, M. Arsenakis, and B. Roizman. 1986. Regulation of herpes simplex virus 1 gene expression: The effect of genomic environments and its implication for model systems. Cancer Cells 14: 163-173.

McKnight, J.L.C., T.M. Kristie, and B. Roizman. 1987. The binding of the virion protein mediating alpha gene induction in herpes simplex virus 1 infected cells to its cis site requires cellular proteins. Proc. Natl. Acad. Sci. 84: 7061-7065.

Mizushima-Sugano, J. and R.G. Roeder. 1986. Cell-type-specific transcription of an immunoglobulin $\kappa$ light chain in vitro. Proc. Natl. Acad. Sci. 83: 8511-8515.

Muller, M.M., S. Ruppert, W. Schaffner, and P. Matthias. 1988. A cloned octamer transcription factor stimulates transcription from lymphoid-specific promoters in non-B cells. $\mathrm{Na}$ ture 336: 544-551.

Murphy, S., C. Di Leigro, and M. Melli. 1987. The in vitro transcription of the 7SK RNA gene by RNA polymerase III is dependent only on the presence of an upstream promoter. Cell 51: 81-87.

O'Hare, P. and C.R. Goding. 1988. Herpes simplex virus regulatory elements and the immunoglobulin octamer domain bind a common factor and are both targets for virus transactivation. Cell 52: 435-445.

Otting, G., Y.Q. Qian, M. Billeter, M. Muller, M. Affolter, W.J. Gehring, and K. Wuthrich. 1990. Protein-DNA contacts in the structure of a homeodomain-DNA complex determined by nuclear magnetic resonance spectroscopy in solution. EMBO I. 9: 3085-3092.

Pellett, P.E., J.L.C. McKnight, F.J. Jenkins, and B. Roizman. 1985. Nucleotide sequence and predicted amino acid sequence of a protein encoded in a small herpes simplex virus DNA fragment capable of trans-inducing alpha genes. Proc. Natl. Acad. Sci. 82: 5870-5874.

Preston, C.M., M.C. Frame, and M.E.M. Campbell. 1988. A complex formed between cell components and an HSV structural polypeptide binds to a viral immediate early gene regulatory DNA sequence. Cell 52: 425-434.

Qian, Y.Q., M. Billeter, G. Otting, M. Mueller, W.J. Gehring, and K. Wuthrich. 1989. The structure of the Antennapedia homeodomain determined by NMR spectroscopy in solution: Comparison with prokaryotic repressors. Cell 59: 573580.

Rosenfeld, M.G. 1991. POU domain transcription factors: POUer-ful developmental regulators. Genes \&) Dev. 5: 897-907.

Scheidereit, C., A. Heguy, and R.G. Roeder. 1987. Identification and purification of a human lymphoid-specific octamerbinding protein (OTF-2) that activates transcription of an immunoglobulin promoter in vitro. Cell 51: 783-793.

Scott, M.P., J.W. Tam Kun, and G.W. Hartzell III. 1989. The structure and function of the homeodomain. Biochim. Biophys. Acta 989: 25-48.

Sive, H.L., N. Heintz, R.G. Roeder. 1986. Multiple sequence elements are required for maximal in vitro transcription of a human histone H2B gene. Mol. Cell Biol. . 6: 3329-3340.

Staudt, L.M., H. Singh, R. Sen, T. Wirth, P.A. Sharp, and D. Baltimore. 1986. A lymphoid-specific protein binding to the octamer motif of immunoglobulin genes. Nature 323: 640643.

Stern, S. and W. Herr. 1991. The herpes simplex virus transactivator VP16 recognizes the Oct-1 homeo domain: Evi- 
dence for a homeo domain recognition subdomain. Genes Dev. 5: 2555-2566.

Stern, S., M. Tanaka, and W. Herr. 1989. The Oct-1 homoeodomain directs formation of a multiprotein-DNA complex with the HSV transactivator VP16. Nature 341: 624-630.

Sturm, R.A., G. Das, and W. Herr. 1988. The ubiquitous octamer-binding protein Oct- 1 contains a POU domain with a homeo box subdomain. Genes \& Dev. 2: 1582-1599.

Treacy, M.N., L.I. Neilson, E.E. Turner, X. He, and M.G. Rosenfeld. 1992. Twin of I-POU: A two amino acid difference in the I-POU homeodomain distinguishes an activator from an inhibitor of transcription. Cell 68: 491-505.

Ullman, K.S., W.M. Flanagan, C.A. Edwards, and G.R. Crabtree. 1991. Activation of early gene expression in $\mathrm{T}$ lymphocytes by Oct- 1 and an inducible protein, $\mathrm{OAP}^{40}$. Science 254: 558 562 .

Voss, J.W., L. Wilson, and M.G. Rosenfeld. 1991. POU domain proteins Pit- 1 and Oct- 1 interact to form a heteromeric complex and can cooperate to induce expression of the prolactin promoter. Genes \& Dev. 5: 1309-1320.

Wirth, T., L. Staudt, and D. Baltimore. 1987. An octamer oligonucleotide upstream of a TATA element is sufficient for lymphoid-specific promoter activity. Nature 329: 174-177.

Wolberger, C., A.K. Vershon, B. Liu, A.D. Johnson, and C.O. Pabo. 1991. Crystal structure of a MAT $\alpha 2$ homeodomainoperator complex suggests a general model for homeodomain-DNA interactions. Cell 67: 517-528.

Xiao, P. and J.P. Capone. 1990. A cellular factor binds to the herpes simplex virus type 1 transactivator Vmw65 and is required for Vmw65-dependent protein-DNA complex assembly with Oct-1. Mol. Cell. Biol. 10: 4974-4977. 


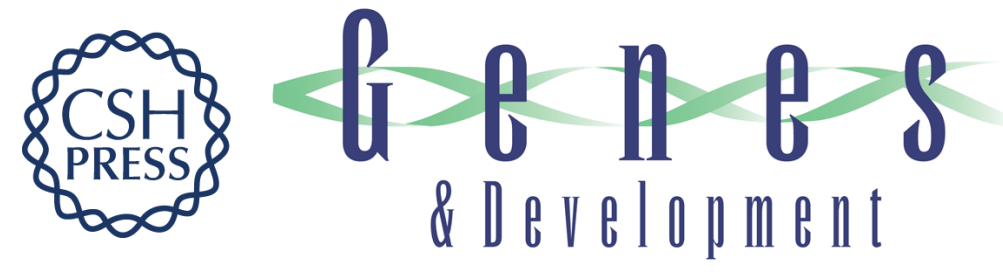

\section{Recognition of the surface of a homeo domain protein.}

J L Pomerantz, T M Kristie and P A Sharp

Genes Dev. 1992, 6:

Access the most recent version at doi:10.1101/gad.6.11.2047

References This article cites 58 articles, 24 of which can be accessed free at: http://genesdev.cshlp.org/content/6/11/2047.full.html\#ref-list-1

License

Email Alerting Receive free email alerts when new articles cite this article - sign up in the box at the top Service right corner of the article or click here.

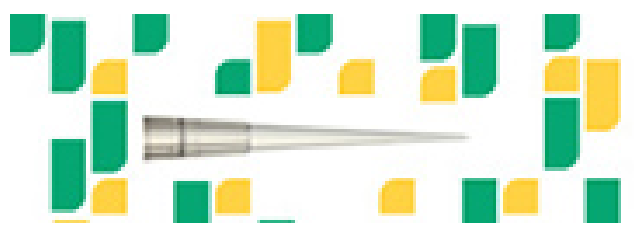

Focused on your science. 